\title{
Translational Evaluation of a Dodecaborated Albumin Conjugate With Maleimide as a Boron Delivery System for a Neutron Capture Reaction to an F98 Rat Glioma Model
}

\section{Hideki Kashiwagi}

Osaka Medical and Pharmaceutical University: Osaka Ika Yakka Daigaku https://orcid.org/0000-00033192-4065

Shinji Kawabata ( $\sim$ shinji.kawabata@ompu.ac.jp)

Osaka Medical and Pharmaceutical University: Osaka Ika Yakka Daigaku https://orcid.org/0000-00015007-5279

\section{Kohei Yoshimura}

Osaka Medical and Pharmaceutical University: Osaka Ika Yakka Daigaku

\section{Yusuke Fukuo}

Osaka Medical and Pharmaceutical University: Osaka Ika Yakka Daigaku

\section{Takuya Kanemitsu}

Osaka Medical and Pharmaceutical University: Osaka Ika Yakka Daigaku

\section{Koji Takeuchi}

Osaka Medical and Pharmaceutical University: Osaka Ika Yakka Daigaku

\section{Ryo Hiramatsu}

Osaka Medical and Pharmaceutical University: Osaka Ika Yakka Daigaku

\section{Kai Nishimura}

Tokyo Institute of Technology: Tokyo Kogyo Daigaku

\section{Kazuki Kawai}

Tokyo Institute of Technology: Tokyo Kogyo Daigaku

\section{Takushi Takata}

Kyoto University: Kyoto Daigaku

Hiroki Tanaka

Kyoto University: Kyoto Daigaku

\section{Tsubasa Watanabe}

Kyoto University: Kyoto Daigaku

\section{Minoru Suzuki}

Kyoto University: Kyoto Daigaku

\section{Shin-Ichi Miyatake}

Kyoto University: Kyoto Daigaku 


\section{Hiroyuki Nakamura}

Tokyo Institute of Technology: Tokyo Kogyo Daigaku

Masahiko Wanibuchi

Osaka Medical and Pharmaceutical University: Osaka Ika Yakka Daigaku

\section{Research Article}

Keywords: Albumin, Boron neutron capture therapy, Dodecaborate, Drug delivery system, Maleimide, Highgrade glioma

Posted Date: October 22nd, 2021

DOl: https://doi.org/10.21203/rs.3.rs-832070/v1

License: (c) (i) This work is licensed under a Creative Commons Attribution 4.0 International License.

Read Full License 


\section{Abstract}

Boron neutron capture therapy (BNCT) is a biologically targeted, cell-selective particle irradiation therapy that utilizes the nuclear capture reaction of boron and neutron. Recently, accelerator neutron generators have been used in clinical settings, and expectations for developing new boron compounds are growing. In this study, we focused on serum albumin, a well-known drug delivery system, and developed maleimide-functionalized closo-dodecaborate albumin conjugate (MID-AC) as a boron carrying system for BNCT. Our biodistribution experiment involved F98 glioma-bearing rat brain tumor models systemically administered with MID-AC and demonstrated accumulation and long retention of boron. Our BNCT study with MID-AC observed statistically significant prolongation of the survival rate compared to the control groups, with results comparable to BNCT study with boronophenylalanine (BPA) which is the standard use of in clinical settings. Each median survival time was as follows: untreated control group; 24.5 days, neutron-irradiated control group; 24.5 days, neutron irradiation following 2.5 hours after termination of intravenous administration (i.v.) of BPA; 31.5 days, and neutron irradiation following 2.5 or 24 hours after termination of i.v. of MID-AC; 33.5 or 33.0 days, respectively. The biological effectiveness factor of MID-AC for F98 rat glioma was estimated based on these survival times and found to be higher to 12. This tendency was confirmed in BNCT 24 hours after MID-AC administration. MID-AC induces an efficient boron neutron capture reaction because the albumin contained in MID-AC is retained in the tumor and has a considerable potential to become an effective delivery system for BNCT in treating high-grade gliomas.

\section{Introduction}

High-grade gliomas are refractory to standard treatments such as chemoradiotherapy after surgical resection. Since high-grade gliomas, especially glioblastoma, diffusely infiltrates and invades normal brain parenchyma, surgery alone cannot remove all tumor cells. Thus postoperative tumor cell-selective treatment plays a very important role [1].

Recently, boron neutron capture therapy (BNCT), targetable at the cellular level with high energy particle beams, have been expected to treat high-grade gliomas. While the usefulness of radiotherapy techniques for high-grade gliomas have been widely known [2,3], BNCT is a particle therapy that uses the reactions produced by boron-10 $\left({ }^{10} \mathrm{~B}\right)$ atoms captured by thermal neutrons to destroy tumor cells selectively. When boron compounds are taken up in tumor cells, irradiation with low-energy thermal neutrons produces alpha particle and recoil lithium-7 ( $\left.{ }^{7} \mathrm{Li}\right)$ nuclei as high linear energy transfer (LET) particles. Since the path length of these high-LET particles is limited to approximately 4-9 $\mu \mathrm{m}$, the cell-killing effect is limited to the boron-containing cells. Therefore, BNCT is very suitable for diseases that require highly biologically targeted therapy, such as high-grade gliomas with a infiltrative nature to the normal brain parenchyma. BNCT using a nuclear reactor has demonstrated its applicability in several clinical trials against highgrade gliomas [4-9]. And also BNCT using an accelerator-based neutron generator has been shown to be effective in treating high-grade gliomas [10]. BNCT using an accelerator-based neutron generator will 
soon become widely available in clinical settings because accelerator-based BNCT systems of can easily be set up in any hospital $[10,11]$.

The most commonly used boron compound is boronophenylalanine (BPA), and it is the only compound that has been approved by the pharmaceutical authorities in Japan $[10,11]$. However, since some clinical cases in which BNCT using BPA are not very effective to such as deep-seated tumors or multiple lesions that require long irradiation times or multi-directional irradiation or BPA-resistant tumor cells exsit, further development of novel boron compounds is a key area of interest for improving the effectiveness of BNCT.

Our studies have focused on serum albumin, already an effective drug delivery system $[12,13]$. We reported that maleimide-functionalized closo-dodecaborate (MID) and albumin conjugate (MID-AC), a serum albumin conjugate of boron compound, can selectively and highly accumulate in a mouse colon tumor 26 subcutaneous. The tumor growth obtained significant inhibition with neutron irradiation after MID-AC administration [14]. Since MID-AC has never been applied to brain tumors before, we evaluated the applicability of MID-AC to gliomas based on the biodistribution of MID-AC and the therapeutic effect of BNCT on F98 rat glioma models.

\section{Materials And Methods}

\section{Boron compounds}

Maleimide-functionalized closo-dodecaborate (MID), which has been successfully synthesized, was mixed with albumin from human serum lyophilized powder (Sigma-Aldrich, Tokyo, Japan) at a ratio of 1:10. The conjugate was subsequently used in several experiments (Maleimide-functionalized closododecaborate albumin conjugate, MID-AC) [14]. BPA (L-isomer) was kindly provided by Stellar Chemifa (Osaka, Japan) and converted into a fructose complex [15]. All boron compounds used in this study were boron-10 concentrates.

\section{Cell Culture}

In this study, we used F98 rat glioma cells because they can infiltrate and invade the normal brain parenchyma of a Fischer rat and are reportedly refractory to various treatments, including radiotherapy. Moreover, F98 rat glioma models progress histologically to undifferentiated or anaplastic gliomas in in vivo pathological histology [16]. They often serve as brain tumor models for evaluating the BNCT therapeutic effects [17-20]. F98 rat glioma cells were kindly provided by Dr. Rolf Barth (The Ohio State University, Columbus, Ohio, USA). The cells were cultured in Dulbecco's Modified Eagle's Medium (DMEM) and supplemented with $10 \%$ fetal bovine serum and penicillin, streptomycin, and amphotericin $\mathrm{B}$ at $37{ }^{\circ} \mathrm{C}$ in an atmosphere of $5 \% \mathrm{CO}_{2}$. All materials were purchased from Gibco Invitrogen (Grand Island, NY, USA).

\section{F98 rat glioma model}

Each 10-week-old male Fischer rat used in this study weighed between 200 and $250 \mathrm{~g}$. The rats were anesthetized by intraperitoneal injection of a mixed anesthetics containing medetomidine (ZENOAQ, 
Fukushima, Japan) $(0.4 \mathrm{mg} / \mathrm{kg})$, midazolam (SANDOZ, Yamagata, Japan) $(2.0 \mathrm{mg} / \mathrm{kg})$, and butorphanol (Meiji Seika, Tokyo, Japan) $(5.0 \mathrm{mg} / \mathrm{kg}$ ). Each head was fixed with a stereotactic frame (Model 900; David Kopf Instruments, Tujunga, CA, USA), and F98 rat glioma cells were implanted into each rat brain. $10^{3} \mathrm{F98}$ rat glioma cells diluted in a $10 \mu \mathrm{L}$ solution of DMEM containing $1.4 \%$ agarose (Wako Pure Chemical Industries, Osaka, Japan) for therapeutic experiments or $10^{5} \mathrm{~F} 98$ rat glioma cells for biodistribution experiments were injected at a rate of $20 \mu \mathrm{L} / \mathrm{min}$ by an automated infusion pump, respectively. Our research groups use these surgical procedures routinely [17-20].

\section{Biodistribution of boron compounds in F98 rat glioma models}

Approximately 12 days post-implantation of $10^{5} \mathrm{~F} 98$ rat glioma cells, when the tumor was expected to have grown sufficiently, each boron compound was administered at the following bodyweight (b.w.) doses: $12 \mathrm{mg}$ boron (B)/kg b.w. for BPA and $20 \mathrm{mg} \mathrm{B/kg} \mathrm{b.w.} \mathrm{for} \mathrm{MID-AC,} \mathrm{respectively.} \mathrm{All} \mathrm{rats} \mathrm{were}$ euthanized at a fixed time, and the tumor, brain, blood, heart, lung, liver, kidney, spleen, skin, and muscle were removed. Consequently, each organ was weighed and digested with $1 \mathrm{~N}$ nitric acid solution. After each organ dissolved sufficiently, the boron concentration was measured by using inductively coupled plasma atomic emission spectroscopy (ICP-AES; iCAP6300 emission spectrometer, Hitachi, Tokyo, Japan). Results were normalized as $\mu \mathrm{g} \mathrm{B/g}$.

\section{Survival analysis of a neutron irradiation experiment for F98 rat glioma models}

This study aimed to evaluate the therapeutic effects of MID-AC on brain tumors. A neutron irradiation experiment was conducted at the nuclear reactor (Institute for Integrated Radiation and Nuclear Science, Kyoto University, Kumatori, Osaka, Japan) for 14 days post-implantation of $10^{3} \mathrm{~F} 98$ rat glioma cells into the cells the brains of Fischer rats. Thirty-five F98 rat glioma models were randomly divided into the following five groups: untreated control group (Untreated), neutron-irradiated control group (Irradiation only), neutron irradiation following 2.5 hours after termination of intravenous administration (i.v.) of BPA (BNCT using BPA $2.5 \mathrm{~h}$ ), and neutron irradiation following 2.5 or 24 hours after termination of i.v. of MIDAC (BNCT using MID-AC $2.5 \mathrm{~h}$ or $24 \mathrm{~h}$ ). Regarding MID-AC, this neutron irradiation experiment was conducted not only following $2.5 \mathrm{~h}$ after termination of i.v. of MID-AC, but also at $24 \mathrm{~h}$, in order to evaluate the effect of the long retention of boron in the tumor. In other words, it was confirmed whether the administration of a boron compound with a long retention time in the tumor would have sufficient BNCT effect even after a long time after administration.

All rats were anesthetized by intraperitoneal injection of a mix of anesthetics described above, and the study groups received BPA or MID-AC. Excluding their heads, all rat bodies were attached on a plate lined with ${ }^{6} \mathrm{LiF}$ ceramic tiles to shield and reduce neutron irradiation, and then neutron irradiation was performed. F98 rat glioma models were irradiated at a reactor power of $5 \mathrm{MW}$ with the Heavy Water Irradiation Facility for 20 minutes. After neutron irradiation, all rats remained under the same experimental conditions as the control groups, and observations continued until their time of death or euthanasia. Finally, the therapeutic effects of BNCT were evaluated by Kaplan-Meier survival curves, and 
the percent increased life span (\%ILS) was determined based on the median survival times (MST). \%ILS was calculated by the equation (MST of each BNCT group - MST of Untreated group) $\times 100 /$ (MST of Untreated group).

\section{Determining the physical dose, estimated photon-equivalent doses, and the compound biological effectiveness based on the in vivo neutron irradiation experiment}

The physical dose was calculated from thermal, epithermal, fast neutrons, and gamma rays contained in the irradiated neutrons. This is calculated by the equation $D_{B}+D_{N}+D_{H}+D_{\gamma}$, which correspond to ${ }^{10} \mathrm{~B}(\mathrm{n}, \mathrm{a})^{7} \mathrm{Li},{ }^{14} \mathrm{~N}(\mathrm{n}, \mathrm{p}){ }^{14} \mathrm{C}$, and ${ }^{1} \mathrm{H}(\mathrm{n}, \mathrm{n}){ }^{1} \mathrm{H}$ capture reactions and $\mathrm{y}$-ray, respectively. More specifically, $\mathrm{D}_{\mathrm{B}}$ is the physical dose of boron derived from the equation of $7.43 \times 10^{-14}\left(\mathrm{~Gy} \mathrm{~cm}^{2} / \mu \mathrm{g}{ }^{10} \mathrm{~B} / \mathrm{g}\right) \times$ boron concentration $\left(\mu \mathrm{g}{ }^{10} \mathrm{~B} / \mathrm{g}\right) \times$ thermal neutron fluence $\left(1 / \mathrm{cm}^{2}\right) . D_{N}$ is the physical dose of nitrogen derived from the equation of $6.78 \times 10^{-14}\left(\mathrm{~Gy} \mathrm{~cm}^{2} /\right.$ weight \%) $\times$ nitrogen concentration (weight \%) $\times$ thermal neutron fluence $\left(1 / \mathrm{cm}^{2}\right) . D_{H}$ is the elastic scattering between epithermal or fast neutrons and the hydrogen nucleus, and $D_{Y}$ is the measured value of gamma rays mixed in the neutron beam [20]. Based on the results of the biodistribution experiments for $\mathrm{F} 98$ rat glioma models, the physical doses to the brain and the tumor of the F98 rat glioma model were calculated in BNCT using BPA $2.5 \mathrm{~h}$, MID-AC $2.5 \mathrm{~h}$, and MID-AC $24 \mathrm{~h}$. The estimated photon-equivalent dose for BNCT using BPA $2.5 \mathrm{~h}$ was calculated by the equation $D_{B} \times$ compound biological effectiveness $(C B E)+D_{N} \times$ relative biological effectiveness of nitrogen $\left(R B E_{N}\right)+D_{H} \times$ relative biological effectiveness of hydrogen $\left(R B E_{H}\right)+D_{Y}$ [20]. CBE is a biological effectiveness factor specific for each irradiated tissue and each boron compound at the neutron capture reaction. Based on the survival time of each group and the estimated photon-equivalent doses in BNCT using BPA $2.5 \mathrm{~h}$, the CBE of MID-AC was calculated by the estimated photon-equivalent doses acquired in BNCT using MID-AC.

\section{Statistical Analysis}

The Kaplan-Meier curve evaluated the MST from the implantation date of F98 rat glioma cells, and logrank tests determined the potentially significant differences among the groups. A $p$-value less than 0.05 were considered statistically significant. Statistical analyses were performed by the JMP® Pro version 15.1.0. software (SAS, Cary, NC, USA).

\section{Results}

\section{Biodistribution of boron compounds in F98 rat glioma models}

Boron concentrations in the tumor, brain, and blood at 2.5, 12, and 24 hours after termination of i.v. of MID-AC were $6.1 \pm 2.0(0.4 \pm 0.1$ in brain and $19.7 \pm 9.8$ in blood), $8.5 \pm 1.5(0.4 \pm 0.1$ in brain and $15.3 \pm 1.0$ in blood), and $6.1 \pm 0.2$ ( $0.6 \pm 0.4$ in brain and $9.9 \pm 1.5$ in blood) $\mu \mathrm{g} \mathrm{B/g}$, respectively. In the case of MID$\mathrm{AC}$, boron concentrations were gradually decreased in almost organs, but it tended to be retained and slowly metabolized in the tumor, kidney, and spleen. Boron concentrations in the tumor, brain, and blood 
after $2.5,6,12$, and 24 hours after termination of i.v. of BPA were $20.6 \pm 2.6(5.5 \pm 0.6$ in brain and $7.7 \pm$ 0.5 in blood), $15.0 \pm 3.4$ (3.7 \pm 0.6 in brain and $4.1 \pm 0.4$ in blood), $9.1 \pm 3.3$ ( $2.5 \pm 0.6$ in brain and $2.9 \pm 0.4$ in blood), $8.2 \pm 0.8(2.3 \pm 0.3$ in brain and $2.9 \pm 0.4$ in blood) $\mu \mathrm{g}$ boron $(\mathrm{B}) / \mathrm{g}$, respectively. The boron concentrations in all organs were highest at 2.5 hours after termination of i.v. of BPA and then immediately decreased due to metabolism by the kidney. Table 1 presents a summary of our results, and Fig. 1 demonstrates boron concentration uptake in each organ.

\section{Survival analysis of a neutron irradiation experiment for F98 rat glioma models}

Neutron irradiation experiments were conducted after administration of each boron compound to the F98 rat glioma models. The treatment effect was evaluated by using Kaplan-Meier survival curves. Each MST was as follows: Untreated; 24.5 days [95\% confidence interval (Cl); 23-27 days], Irradiation only; 24.5 days [ $95 \% \mathrm{Cl} ; 23-27$ days], BNCT using BPA $2.5 \mathrm{~h} ; 31.5$ days [ $95 \% \mathrm{Cl} ; 28-40$ days], BNCT using MIDAC 2.5 h; 33.5 days [95\% Cl; 23-40 days], and BNCT using MID-AC 24 h; 33.0 days [95\% Cl; $27-36$ days]. Statistically significant differences were observe between Untreated and BNCT using MID-AC groups (vs. BNCT using MID-AC $2.5 h, p=0.0019$; vs. BNCT using MID-AC $24 h, p=0.0005$, respectively, log-rank test). BPA, used as a capture compound, also showed a significant survival gain (vs. BNCT using BPA $2.5 \mathrm{~h}, \mathrm{p}<$ 0.0001). MSTs did not demonstrate any significant differences in BNCT using MID-AC $2.5 \mathrm{~h}$ or $24 \mathrm{~h}$ compared to BNCT using BPA $2.5 \mathrm{~h}$ (vs. BNCT using MID-AC $2.5 \mathrm{~h}, \mathrm{p}=0.94$; vs. BNCT using MID-AC $24 \mathrm{~h}$, $p=0.67$, respectively, log-rank test). Each \%ILS value was as follows: BNCT using BPA 2.5 h; $28.6 \%$, BNCT using MID-AC 2.5 h; 36.7\%, and BNCT using MID-AC 24 h; 34.7\%. Table 2 and Fig. 2 show the detailed results and the Kaplan-Meier survival curves.

\section{Determining the physical dose, estimated photon-equivalent doses, and the CBE based on the in vivo neutron irradiation experiment}

$\mathrm{RBE}_{\mathrm{N}}$ and $\mathrm{RBE}_{\mathrm{H}}$ have been adapted to 3.0 [21]. The CBE for the normal brain tissue from BPA was 1.35 [4], and the CBE for the brain tumor from BPA was $3.8[4,22]$. There was no statistically significant difference in the respective MSTs in BNCT groups. Therefore, we assumed the estimated photonequivalent doses of brain tumor were also equivalent between BNCT using BPA $2.5 \mathrm{~h}$ and BNCT using MID-AC at $2.5 \mathrm{~h}$ or $24 \mathrm{~h}$ after the neutron irradiation experiment for $\mathrm{F} 98$ rat glioma models. Based on this assumption, the estimated photon-equivalent dose of the brain tumor obtained by BNCT using BPA $2.5 \mathrm{~h}$ was $10.8 \mathrm{~Gy}$-Eq. Consequently, CBE of MID-AC was estimated from in vivo survival to be 13.4 at MID-AC $2.5 \mathrm{~h}$ and 12.3 at MID-AC $24 \mathrm{~h}$, respectively. Table 3 presents a summary of these results.

\section{Discussion}

We investigated a promising albumin conjugate of maleimide-functionalized closo-dodecaborate, named MID-AC, as a boron delivery compound to improve the efficacy of BNCT against high-grade gliomas. When assessing boron compounds in clinical and pre-clinical trials, it is essential to consider the biological effects of BNCT, which can be represented by the CBE value specific for each combination of 
irradiated tissue and boron compound at the neutron capture reaction. Previous clinical investigations on BNCT for high-grade gliomas determined that the CBE value of BPA was 3.8 [15]. In the in vivo neutron irradiation study, BNCT groups obtained statistically significant prolongation compared to Untreated (Table 2). Each BNCT using a MID-AC group demonstrated higher values in both MST and \%ILS than BNCT using BPA $2.5 \mathrm{~h}$; however, these differences were not significant (Fig. 2). Therefore, based on the neutron irradiation experiments of F98 rat glioma models, the estimated photon-equivalent doses were approximated to calculate the compound-specific CBE factor of MID-AC for brain tumors. Briefly, the estimated photon-equivalent dose acquired by BNCT using BPA $2.5 \mathrm{~h}$ was regarded as equivalent to the doses acquired by BNCT using MID-AC $2.5 \mathrm{~h}$ or $24 \mathrm{~h}$. The compound-specific CBE factors were calculated to be 13.4 (MID-AC $2.5 \mathrm{~h}$ ) and 12.3 (MID-AC $24 \mathrm{~h}$ ), respectively. Our study identified that the efficient cellkilling effect of MID-AC in BNCT might contribute to the CBE value, which is approximately 3-3.5 times higher compared to BPA. While MID-AC provides an efficient boron neutron capture reaction, the boron concentration delivered to the brain tumor cells is still of low level. Improving MID-AC to provide more boron to brain tumor cells would further enhance the effcacy of BNCT against high-grade gliomas.

Serum albumin, contained in MID-AC, has been frequently used as a drug delivery system $[12,13]$. The delivery method of serum albumin to tumor tissues is passive as a result of the enhanced permeability and retention (EPR) effect [23, 24], but also active due to secreted protein acidic and rich in cysteine (SPARC) and gp60 receptors [12]. These receptors are known to be highly expressed in high-grade glioma cells, and treatment with albumin-containing compounds using SPARC, which is a target of active transport [25]. Some albumin-containing compounds have allowed the fluorescent diagnosis of highgrade gliomas $[13,26]$. Moreover, the conjugate of boron-dipyrromethene dyes (BODIPY), which has been used as a fluorescent imaging probe for cancer diagnosis [27], and human serum albumin have proved their efficacy as suitable imaging probes and boron compounds for BNCT [28]. Therefore, applying these visualization techniques may be able to allow clinicians to evaluate the eligibility of BNCT-related compounds in treating cancerous lesions. While exploiting albumin's ability to deliver boron compounds to high-grade gliomas, we have focused on a maleimide with a high binding affinity to albumin. Consequently, we have synthesized maleimide-functionalized closo-dodecaborate (MID) as a boron compound and conjugated it to the serum albumin at Cys34 [14]. Since fluorescent-labeled MIDconjugated bovine serum albumin has been also found to accumulate in the cytosol of HeLa cells [29], visualization techniques using MID are bound to be established in the future.

In terms of boron distribution, the boron concentrations of the tumor were almost equal at 2.5 and 24 hours after systemic administration of MID-AC, while those of the tumor were decreased with time after systemic administration of BPA (Table 1 and Fig. 1). This result suggests that MID-AC is transferred from the blood vessel to the tumor tissue, and MID-AC is retained in tumor cells for an extended period. At the same time, the maximum concentration of boron in each organ was approximately $20 \mu \mathrm{g} \mathrm{B} / \mathrm{g}$ suggests that toxicity to the body was not high (Fig. 1). As a result, in the case of MID-AC, the long time boron retention in the tumor renders it possible to continuously and steadily acquire boron neutron capture reactions for a long time while neutrons are irradiated. In addition, BPA contains one boron atom, whereas MID-AC contains twelve boron atoms per molecule obtained from dodecaborate. Considering that one 
molecule from each compound is taken up by one tumor cell, the probability of a capture reaction is higher for compounds containing more boron atoms per molecule, thus facilitating a higher antitumor effect.

Suitable requirements for BNCT boron compounds are low intrinsic toxicity, high boron accumulation for target lesions, low uptake into normal tissues, and water solubility [17, 30]. In addition, it is also important to consider the method of delivering compounds into the tumor cells because both the blood-brain barrier (BBB) and the blood-brain tumor barrier (BBTB) prevent the uptake of compounds [31-33]. In high-grade gliomas, since the BBB or BBTB is locally disrupted at the core of the tumor bulk, chemical compounds containing boron could be transported to the tumor cells. However, glioma cells tend to infiltrate into the normal brain parenchyma where the BBB is still intact, and thus delivery of these compounds can be very challenging. Apart from these requirements and provided that boron compounds can remain in the tumor for a substantial period of time, irradiation times can be easily adjusted, thus expanding the respective therapeutic range. As a result, novel boron compounds must meet as many of these requirements as possible. Only two compounds, BPA and sodium borocaptate (BSH), are currently used in clinical BNCT $[30,34]$. For a long time now, a wide variety of boron delivery compounds, amino acids, liposomes, porphyrins, and serum albumin conjugates, etc., have been developed and studied as they could be more effective in BNCT. But still, the most commonly used boron compound is BPA, and it is the only compound that has been approved by the pharmaceutical authorities in Japan [10,11].

BPA almost meets the requirements above however BPA-resistant brain tumor cells sometimes exist. Therefore, the development of tumor-targeting boron compounds generated by different approaches should address and treat BPA-resistant brain tumor cells in biologically targeted therapy, BNCT. In BNCT for high-grade gliomas, BSH utilizes BBB breakdown and is not cell-selective [30]. Although many boron compounds were developed and studied, only a few of them can be as effective as or even more effective than BPA when administered intravenously in the BNCT animal model of high-grade glioma [17]. MID-AC targets tumors with a different mechanism than BPA and has a very attractive and promising compound delivery capacity in BNCT of high-grade gliomas, showing comparable results to BPA even by intravenous administration. In addition, since the efficacy of BNCT was similar at 2.5 hours and 24 hours after MID$A C$ administration, variable neutron irradiation times can be available without the necessity of continuously administrating boron compounds. Since MID-AC is deemed to be very safe, it is expected to be useful in clinical practice when establishing protocols that involve larger doses, longer doses, and repeated administration. Such modification approaches are difficult to achieve with a compound that has a very rapid clearance rate, although this may also be advantageous for BPA. MID-AC properties such as long retention in tumor cells and high tumor cell selectivity can enable treatment of deep-seated tumors that require long irradiation times or multi-directional irradiation.

\section{Conclusion}

MID-AC, a dodecaborated albumin conjugate with maleimide, can efficiently induce boron neutron capture reactions into the tumor cell nucleus and, thus, be effective against brain tumor cells. The long 
time retention of MID-AC in tumor cells renders it possible to continuously acquire stable boron neutron capture reactions for a long time while neutrons are irradiated. Therefore, MID-AC has a considerable potential to become an effective delivery system for BNCT in treating high-grade gliomas.

\section{Declarations}

\section{Funding}

This research was funded by the Japan Society for the Promotion of Science (JSPS) KAKENHI Grant Number JP20H03797 to S.K. [Grants-in-Aid for Scientific Research (B)] and JP20K17945 to T.K. [Grantsin-Aid for Young Scientists].

\section{Conflicts of interest/Competing interests}

All authors declare that they have no conflicts of interest.

\section{Availability of data and material}

The datasets analysed during the current study are available from the corresponding author on reasonable request.

\section{Code availability}

The JMP® Pro version 15.1.0. software (SAS, Cary, NC, USA) was used for statistical analysis.

\section{Authors' Contributions}

H.K., H.N., M.S., and S.K. made substantial contributions to the study conception and design. H.K. K.Y., Y.F., T.K., K.T., R.H., and S.K established this study's methodology. K.N., K.K., and H.N. conceived the concept of manufacturing MID and established the manufacturing process. H.K. and H.N. conducted formal analysis, investigation, and data curation. H.K. and S.K. wrote the original draft preparation. T.T., H.T., T.W., and M.S. wrote, reviewed, and edited the manuscript and supervised the neutron irradiation experiments. S.I.M. and M.W. supervised this project. S.K. and T.K. acquired funding. All authors read and approved the submitted version.

\section{Ethics approval}

All animal experiments complied with the guide for the care and use of laboratory animals approved by the Animal Use Review Board and Ethical Committee of Osaka Medical and Pharmaceutical University (License No. 2019-029) and the Institute for Integrated Radiation and Nuclear Science, Kyoto University (KURNS; Kumatori, Osaka, Japan) (License No. 2019-9).

\section{Consent to participate}

Not applicable. 


\section{Consent for publication}

Not applicable.

\section{Acknowledgments}

Our work was partly performed under the Research Program for Next Generation Young Scientists of "Dynamic Alliance for Open Innovation Bridging Human, Environment and Materials" in "Network Joint Research Center for Materials and Devices" with funds for H.K. supervised by H.N.

\section{References}

1. Stupp R, Hegi ME, Mason WP, Van Den Bent MJ, Taphoorn MJ, Janzer RC, Ludwin SK, Allgeier A, Fisher B, Belanger K, Hau P, Brandes AA, Gijtenbeek J, Marosi C, Vecht CJ, Mokhtari K, Wesseling P, Villa S, Eisenhauer E, Gorlia T, Weller M, Lacombe D, Cairncross JG, Mirimanoff RO, Groups EOFRaTOCBTaRO, and Group NCIOCCT (2009) Effects of radiotherapy with concomitant and adjuvant temozolomide versus radiotherapy alone on survival in glioblastoma in a randomised phase III study: 5-year analysis of the EORTC-NCIC trial. Lancet Oncol. 10(5):459-466. https://doi.org/10.1016/S1470-2045(09)70025-7

2. Walker MD, Alexander E, Hunt WE, Maccarty CS, Mahaley MS, Mealey J, Norrell HA, Owens G, Ransohoff J, Wilson CB, Gehan EA, and Strike TA (1978) Evaluation of BCNU and/or radiotherapy in the treatment of anaplastic gliomas. A cooperative clinical trial. J. Neurosurg. 49(3):333-343. https://doi.org/10.3171/jns.1978.49.3.0333

3. Taunk NK, Moraes FY, Escorcia FE, Mendez LC, Beal K, and Marta GN (2016) External beam reirradiation, combination chemoradiotherapy, and particle therapy for the treatment of recurrent glioblastoma. Expert Rev. Anticancer Ther. 16(3):347-358. https://doi.org/10.1586/14737140.2016.1143364

4. Kawabata S, Miyatake S-I, Kuroiwa T, Yokoyama K, Doi A, lida K, Miyata S, Nonoguchi N, Michiue H, Takahashi M, Inomata T, Imahori Y, Kirihata M, Sakurai Y, Maruhashi A, Kumada H, and Ono K (2009) Boron Neutron Capture Therapy for Newly Diagnosed Glioblastoma. J. Radiat. Res. (Tokyo) 50(1):5160. https://doi.org/10.1269/jrr.08043

5. Henriksson R, Capala J, Michanek A, LindahI SA, Salford LG, Franzén L, Blomquist E, Westlin JE, Bergenheim AT, and Group SBTS (2008) Boron neutron capture therapy (BNCT) for glioblastoma multiforme: a phase II study evaluating a prolonged high-dose of boronophenylalanine (BPA). Radiother. Oncol. 88(2):183-191. https://doi.org/10.1016/j.radonc.2006.04.015

6. Yamamoto T, Nakai K, Kageji T, Kumada H, Endo K, Matsuda M, Shibata Y, and Matsumura A (2009) Boron neutron capture therapy for newly diagnosed glioblastoma. Radiother. Oncol. 91(1):80-84. https://doi.org/10.1016/j.radonc.2009.02.009

7. Sköld K, Gorlia T, Pellettieri L, Giusti V, H-Stenstam B, and Hopewell JW (2010) Boron neutron capture therapy for newly diagnosed glioblastoma multiforme: an assessment of clinical potential. Br. J. 
Radiol. 83(991):596-603. https://doi.org/10.1259/bjr/56953620

8. Miyatake S-I, Kawabata S, Yokoyama K, Kuroiwa T, Michiue H, Sakurai Y, Kumada H, Suzuki M, Maruhashi A, Kirihata M, and Ono K (2009) Survival benefit of Boron neutron capture therapy for recurrent malignant gliomas. J. Neurooncol. 91(2):199-206. https://doi.org/10.1007/s11060-0089699-x

9. Pellettieri L, H-Stenstam B, Rezaei A, Giusti V, and Sköld K (2008) An investigation of boron neutron capture therapy for recurrent glioblastoma multiforme. Acta Neurol. Scand. 117(3):191-197. https://doi.org/10.1111/j.1600-0404.2007.00924.x

10. Kawabata S, Suzuki M, Hirose K, Tanaka H, Kato T, Goto H, Narita Y, and Miyatake S-I (2021) Accelerator-based BNCT for patients with recurrent glioblastoma: a multicenter phase II study. NeuroOncology Advances. 10.1093/noajnl/vdab067. https://doi.org/10.1093/noajnl/vdab067

11. Hirose K, Konno A, Hiratsuka J, Yoshimoto S, Kato T, Ono K, Otsuki N, Hatazawa J, Tanaka H, Takayama K, Wada H, Suzuki M, Sato M, Yamaguchi H, Seto I, Ueki Y, Iketani S, Imai S, Nakamura T, Ono T, Endo H, Azami Y, Kikuchi Y, Murakami M, and Takai Y (2021) Boron neutron capture therapy using cyclotron-based epithermal neutron source and borofalan (Radiother. Oncol. 155:182-187. https://doi.org/10.1016/j.radonc.2020.11.001

12. Lin T, Zhao P, Jiang Y, Tang Y, Jin H, Pan Z, He H, Yang VC, and Huang Y (2016) Blood-Brain-BarrierPenetrating Albumin Nanoparticles for Biomimetic Drug Delivery via Albumin-Binding Protein Pathways for Antiglioma Therapy. ACS Nano 10(11):9999-10012.

https://doi.org/10.1021/acsnano.6b04268

13. Elsadek B and Kratz F (2012) Impact of albumin on drug delivery--new applications on the horizon. J. Control. Release 157(1):4-28. https://doi.org/10.1016/j.jconrel.2011.09.069

14. Kikuchi S, Kanoh D, Sato S, Sakurai Y, Suzuki M, and Nakamura H (2016) Maleimide-functionalized closo-dodecaborate albumin conjugates (MID-AC): Unique ligation at cysteine and lysine residues enables efficient boron delivery to tumor for neutron capture therapy. J. Control. Release 237:160167. https://doi.org/10.1016/j.jconrel.2016.07.017

15. Coderre JA, Button TM, Micca PL, Fisher CD, Nawrocky MM, and Liu HB (1994) Neutron capture therapy of the $9 \mathrm{~L}$ rat gliosarcoma using the p-boronophenylalanine-fructose complex. Int. J. Radiat. Oncol. Biol. Phys. 30(3):643-652. https://doi.org/10.1016/0360-3016(92)90951-d

16. Barth RF and Kaur B (2009) Rat brain tumor models in experimental neuro-oncology: the C6, 9L, T9, RG2, F98, BT4C, RT-2 and CNS-1 gliomas. J. Neurooncol. 94(3):299-312. https://doi.org/10.1007/s11060-009-9875-7

17. Takeuchi K, Hattori Y, Kawabata S, Futamura G, Hiramatsu R, Wanibuchi M, Tanaka H, Masunaga S-I, Ono K, Miyatake S-I, and Kirihata M (2020) Synthesis and Evaluation of Dodecaboranethiol Containing Kojic Acid (KA-BSH) as a Novel Agent for Boron Neutron Capture Therapy. Cells 9(6):1551. https://doi.org/10.3390/cells9061551

18. Fukuo Y, Hattori Y, Kawabata S, Kashiwagi H, Kanemitsu T, Takeuchi K, Futamura G, Hiramatsu R, Watanabe T, Hu N, Takata T, Tanaka H, Suzuki M, Miyatake S-I, Kirihata M, and Wanibuchi M (2020) 
The Therapeutic Effects of Dodecaborate Containing Boronophenylalanine for Boron Neutron Capture Therapy in a Rat Brain Tumor Model. Biology 9(12):437.

https://doi.org/10.3390/biology9120437

19. Kanemitsu T, Kawabata S, Fukumura M, Futamura G, Hiramatsu R, Nonoguchi N, Nakagawa F, Takata T, Tanaka H, Suzuki M, Masunaga S-I, Ono K, Miyatake S-I, Nakamura H, and Kuroiwa T (2019) Folate receptor-targeted novel boron compound for boron neutron capture therapy on F98 glioma-bearing rats. Radiat. Environ. Biophys. 58(1):59-67. https://doi.org/10.1007/s00411-0180765-2

20. Futamura G, Kawabata S, Nonoguchi N, Hiramatsu R, Toho T, Tanaka H, Masunaga S-I, Hattori Y, Kirihata M, Ono K, Kuroiwa T, and Miyatake S-I (2017) Evaluation of a novel sodium borocaptatecontaining unnatural amino acid as a boron delivery agent for neutron capture therapy of the F98 rat glioma. Radiation Oncology 12(1). https://doi.org/10.1186/s13014-017-0765-4

21. Suzuki M, Kato I, Aihara T, Hiratsuka J, Yoshimura K, Niimi M, Kimura Y, Ariyoshi Y, Haginomori SI, Sakurai Y, Kinashi Y, Masunaga SI, Fukushima M, Ono K, and Maruhashi A (2014) Boron neutron capture therapy outcomes for advanced or recurrent head and neck cancer. J. Radiat. Res. (Tokyo) 55(1):146-153. https://doi.org/10.1093/jrr/rrt098

22. Coderre JA, Makar MS, Micca PL, Nawrocky MM, Liu HB, Joel DD, Slatkin DN, and Amols HI (1993) Derivations of relative biological effectiveness for the high-let radiations produced during boron neutron capture irradiations of the $9 \mathrm{~L}$ rat gliosarcoma in vitro and in vivo. Int. J. Radiat. Oncol. Biol. Phys. 27(5):1121-1129. https://doi.org/10.1016/0360-3016(93)90533-2

23. Matsumura $Y$ and Maeda $H$ (1986) A new concept for macromolecular therapeutics in cancer chemotherapy: mechanism of tumoritropic accumulation of proteins and the antitumor agent smancs. Cancer Res. 46(12 Pt 1):6387-6392.

24. Maeda H (2021) The 35th Anniversary of the Discovery of EPR Effect: A New Wave of Nanomedicines for Tumor-Targeted Drug Delivery-Personal Remarks and Future Prospects. J Pers Med 11(3). https://doi.org/10.3390/jpm11030229

25. Park CR, Kim HY, Song MG, Lee YS, Youn H, Chung JK, Cheon GJ, and Kang KW (2020) Efficacy and Safety of Human Serum Albumin-Cisplatin Complex in U87MG Xenograft Mouse Models. Int. J. Mol. Sci. 21(21). https://doi.org/10.3390/ijms21217932

26. Ichioka T, Miyatake S, Asai N, Kajimoto Y, Nakagawa T, Hayashi H, and Kuroiwa T (2004) Enhanced detection of malignant glioma xenograft by fluorescein-human serum albumin conjugate. J. Neurooncol. 67(1-2):47-52. https://doi.org/10.1023/b:neon.0000021783.62610.1b

27. Loudet A and Burgess K (2007) BODIPY dyes and their derivatives: syntheses and spectroscopic properties. Chem. Rev. 107(11):4891-4932. https://doi.org/10.1021/cr078381n

28. Raskolupova VI, Popova TV, Zakharova OD, Nikotina AE, Abramova TV, and Silnikov VN (2021) Human Serum Albumin Labelling with a New BODIPY Dye Having a Large Stokes Shift. Molecules 26(9). https://doi.org/10.3390/molecules26092679 
29. Ishii S, Sato S, Asami H, Hasegawa T, Kohno JY, and Nakamura H (2019) Design of S-S bond containing maleimide-conjugated closo-dodecaborate (SSMID): identification of unique modification sites on albumin and investigation of intracellular uptake. Org. Biomol. Chem. 17(22):5496-5499. https://doi.org/10.1039/c9ob00584f

30. Barth RF, Mi P, and Yang W (2018) Boron delivery agents for neutron capture therapy of cancer. Cancer Commun. 38(1):35. https://doi.org/10.1186/s40880-018-0299-7

31. Wang $D$, Wang $C$, Wang $L$, and Chen $Y$ (2019) A comprehensive review in improving delivery of smallmolecule chemotherapeutic agents overcoming the blood-brain/brain tumor barriers for glioblastoma treatment. Drug Deliv 26(1):551-565. https://doi.org/10.1080/10717544.2019.1616235

32. Pardridge WM (2012) Drug transport across the blood-brain barrier. J. Cereb. Blood Flow Metab. 32(11):1959-1972. https://doi.org/10.1038/jcbfm.2012.126

33. Van Tellingen O, Yetkin-Arik B, De Gooijer MC, Wesseling P, Wurdinger T, and De Vries HE (2015) Overcoming the blood-brain tumor barrier for effective glioblastoma treatment. Drug Resist Updat 19:1-12. https://doi.org/10.1016/j.drup.2015.02.002

34. Barth RF, H Vicente M, Harling OK, Kiger W, Riley KJ, Binns PJ, Wagner FM, Suzuki M, Aihara T, Kato I, and Kawabata S (2012) Current status of boron neutron capture therapy of high grade gliomas and recurrent head and neck cancer. Radiation Oncology 7(1):146. https://doi.org/10.1186/1748-717x-7146

\section{Tables}


Summary of the boron concentrations after intravenous administration of each boron compound on the F98 rat glioma model.

\begin{tabular}{|c|c|c|c|c|c|c|c|}
\hline \multirow{2}{*}{$\begin{array}{l}\text { Boron } \\
\text { compound }^{\text {a }}\end{array}$} & \multirow[t]{2}{*}{ Time $(h)^{b}$} & \multirow[t]{2}{*}{$n^{c}$} & \multicolumn{3}{|c|}{ Boron concentrations $\pm S D(\mu g B / g)^{d}$} & \multicolumn{2}{|l|}{ Ratio } \\
\hline & & & Tumor & Brain & Blood & $\mathrm{T} / \mathrm{Br}{ }^{\mathrm{e}}$ & $T /\left.B\right|^{f}$ \\
\hline \multirow[t]{3}{*}{ MID-AC } & 2.5 & 5 & $6.1 \pm 2.0$ & $0.4 \pm 0.1$ & $19.7 \pm 9.8$ & 17.6 & 0.3 \\
\hline & 12 & 4 & $8.5 \pm 1.5$ & $0.4 \pm 0.1$ & $15.3 \pm 1.0$ & 19.7 & 0.6 \\
\hline & 24 & 3 & $6.1 \pm 0.2$ & $0.6 \pm 0.4$ & $9.9 \pm 1.5$ & 10.4 & 0.6 \\
\hline \multirow[t]{4}{*}{ BPA } & 2.5 & 4 & $20.6 \pm 2.2$ & $5.5 \pm 0.6$ & $7.7 \pm 0.5$ & 3.8 & 2.7 \\
\hline & 6 & 4 & $15.0 \pm 3.4$ & $3.7 \pm 0.6$ & $4.1 \pm 0.4$ & 4.1 & 3.7 \\
\hline & 12 & 4 & $9.1 \pm 3.3$ & $2.5 \pm 0.6$ & $2.9 \pm 0.4$ & 3.7 & 3.2 \\
\hline & 24 & 4 & $8.2 \pm 0.8$ & $2.3 \pm 0.3$ & $2.9 \pm 0.4$ & 3.6 & 2.8 \\
\hline
\end{tabular}

a Each boron compound used was administered at the following body weight (b.w.) doses; $20 \mathrm{mg}$ $\mathrm{B} / \mathrm{kg}$ b.w. for maleimide-functionalized closo-dodecaborate albumin conjugate (MID-AC), $12 \mathrm{mg}$ boron (B)/kg b.w. for boronophenylalanine (BPA), respectively.

$\mathrm{b}$ Time indicates the period from the time of intravenous administration of each boron compound to the time of euthanasia of F98 rat glioma models.

${ }^{\mathrm{c}} \mathrm{n}$ indicates Number of Fischer rats.

${ }^{\mathrm{d}}$ Boron concentration $\pm \mathrm{SD}(\mu \mathrm{g} \mathrm{B} / \mathrm{g})$ is the value measured by ICP-AES for the acquired boron concentration of each organ listed in the table, and is expressed as the mean boron values $(\mu \mathrm{g} \mathrm{B} \mathrm{/}$ gram: weight of organ) \pm standard deviation.

e $\mathrm{T} / \mathrm{Br}$ indicates the tumor to brain ratio.

${ }^{\mathrm{f}} \mathrm{T} / \mathrm{Bl}$ indicates the tumor to blood ratio. 
Table 2

Survival times of the F98 rat glioma model after the neutron irradiation experiment.

\begin{tabular}{|c|c|c|c|c|c|c|}
\hline \multirow[t]{2}{*}{ Group } & \multirow[t]{2}{*}{$n^{a}$} & \multicolumn{3}{|c|}{ Survival times (days) } & \multirow[t]{2}{*}{$\%^{\prime L S}{ }^{c}$} & \multirow[t]{2}{*}{ p-value ${ }^{d}$} \\
\hline & & Mean \pm SD & Median & $95 \% \mathrm{Cl}^{\mathrm{b}}$ & & \\
\hline Untreated & 6 & $24.8 \pm 1.3$ & 24.5 & $23-27$ & - & - \\
\hline Irradiation only & 6 & $24.7 \pm 1.3$ & 24.5 & $23-27$ & - & 0.90 \\
\hline BNCT using BPA $2.5 \mathrm{~h}$ & 8 & $33.1 \pm 4.8$ & 31.5 & $28-40$ & 28.6 & $<0.0001$ \\
\hline BNCT using MID-AC $2.5 \mathrm{~h}$ & 8 & $33.0 \pm 6.2$ & 33.5 & $23-40$ & 36.7 & 0.0019 \\
\hline BNCT using MID-AC $24 \mathrm{~h}$ & 7 & $33.0 \pm 3.3$ & 33.0 & $27-36$ & 34.7 & 0.0005 \\
\hline \multicolumn{7}{|c|}{ a $\mathrm{n}$ indicates Number of Fischer rats. } \\
\hline \multicolumn{7}{|l|}{${ }^{\mathrm{b}} \mathrm{Cl}$ is confidence interval. } \\
\hline \multicolumn{7}{|c|}{$\begin{array}{l}{ }^{c} \text { The percent increased life span (\%ILS) was defined relative to the median survival times (MST) of } \\
\text { Untreated. \%ILS was calculated by the equation (MST of each BNCT group - MST of Untreated group) } \\
\times 100 / \text { (MST of Untreated group). }\end{array}$} \\
\hline
\end{tabular}


Table 3

Summary of the physical dose and the estimated photon-equivalent dose for the brain or the tumor in the F98 rat glioma model.

\begin{tabular}{|c|c|c|c|c|}
\hline \multirow[t]{2}{*}{ Group } & \multicolumn{2}{|c|}{$\begin{array}{l}\text { Physical dose }{ }^{a} \\
\text { (Gy) }\end{array}$} & \multicolumn{2}{|c|}{$\begin{array}{l}\text { Photon-equivalent dose } \\
\text { (Gy-Eq) }\end{array}$} \\
\hline & Brain & Tumor & Brain & Tumor \\
\hline Untreated & 0.0 & 0.0 & 0.0 & 0.0 \\
\hline Irradiation only & 0.8 & 0.8 & 1.3 & 1.3 \\
\hline BNCT using BPA $2.5 \mathrm{~h}$ & 1.6 & 3.3 & 2.5 & 10.8 \\
\hline BNCT using MID-AC $2.5 \mathrm{~h}$ & 0.9 & 1.6 & - & - \\
\hline BNCT using MID-AC $24 \mathrm{~h}$ & 1.0 & 1.7 & - & - \\
\hline \multicolumn{5}{|c|}{$\begin{array}{l}\text { a The physical dose is attributed to the }{ }^{10} \mathrm{~B}(\mathrm{n}, \mathrm{a}){ }^{7} \mathrm{Li},{ }^{14} \mathrm{~N}(\mathrm{n}, \mathrm{p}){ }^{14} \mathrm{C} \text {, and }{ }^{1} \mathrm{H}(\mathrm{n}, \mathrm{n}){ }^{1} \mathrm{H} \text { reactions produced } \\
\text { by the thermal, epithermal, and fast neutron fluxes, and gamma rays in the irradiated neutrons. It is } \\
\text { calculated by using following equation: Physical radiation dose }(\mathrm{Gy})=D_{B}+D_{N}+D_{H}+D_{Y} . D_{B} \text { is boron } \\
\text { dose. } D_{N} \text { : is neutron dose. } D_{H} \text { is hydrogen dose. } D_{Y} \text { is gamma-ray dose. }\end{array}$} \\
\hline \multicolumn{5}{|c|}{$\begin{array}{l}\text { b The estimated photon-equivalent dose is calculated by using following equation: } D_{B} \times \text { compound } \\
\text { biological effectiveness }(C B E)+D_{N} \times \text { relative biological effect of nitrogen }\left(R B E_{N}\right)+D_{H} \times \text { relative } \\
\text { biological effect of hydrogen }\left(R B E_{H}\right)+D_{Y} \text {. RBE } E_{N} \text { and RBE } E_{H} \text { are } 3.0 \text {. In the case of } B P A \text {, the CBE for the } \\
\text { normal brain tissue is } 1.35 \text { and the } C B E \text { for the brain tumor is } 3.8 \text { in BPA. }\end{array}$} \\
\hline
\end{tabular}

\section{Figures}



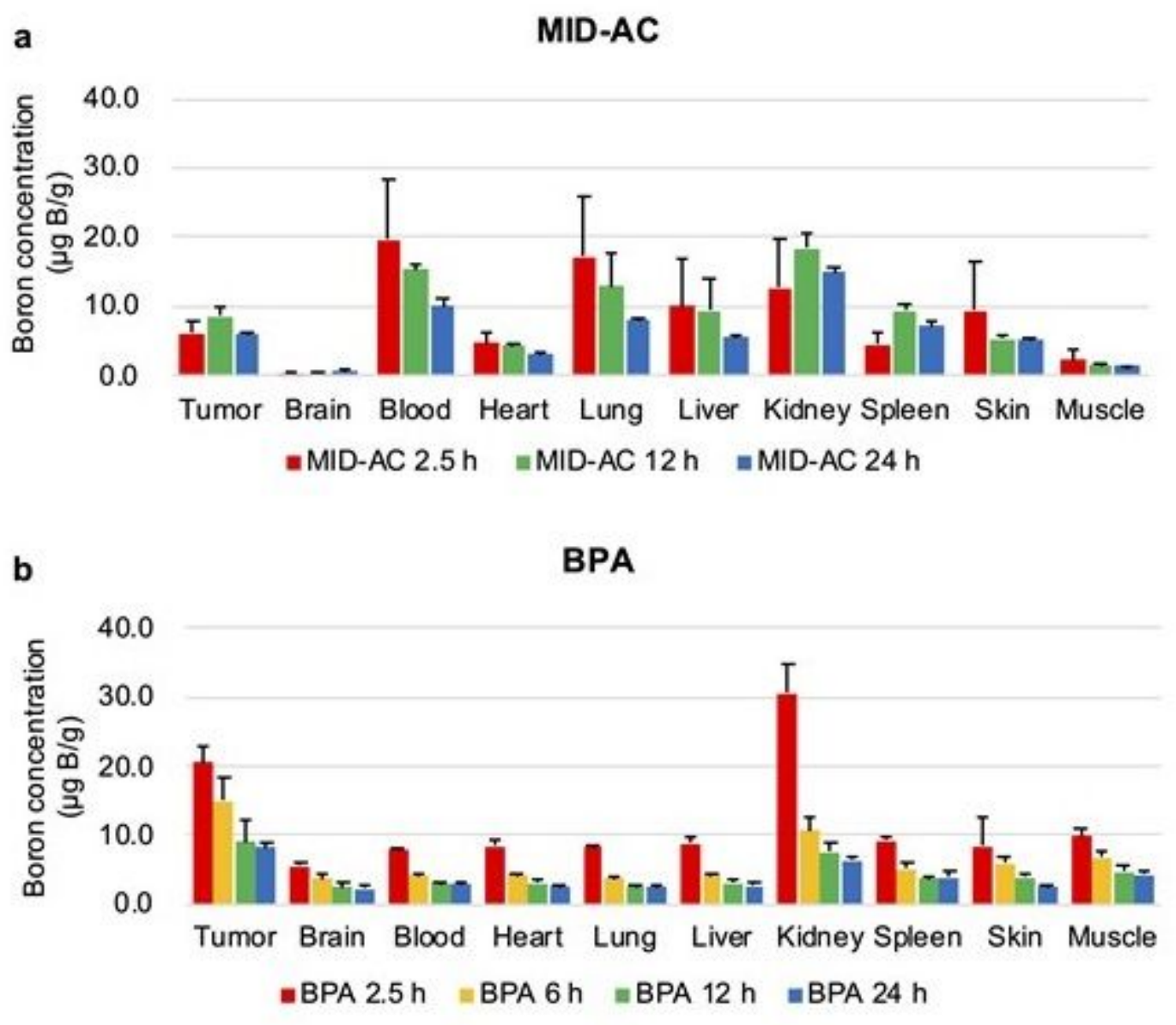

Figure 1

Transition of boron concentrations in each organ in the F98 glioma model after each boron compond administration. Each boron compound was administered to a Fischer rat bearing intracranial implants of $105 \mathrm{F9} 8$ rat glioma cells at the following body weight (b.w.) doses. (a) $20 \mathrm{mg}$ boron (B)/kg b.w. for maleimide-functionalized closo-dodecaborate albumin conjugate (MID-AC). (b) $12 \mathrm{mg} \mathrm{B} / \mathrm{kg} \mathrm{b.w.} \mathrm{for}$ boronophenylalanine (BPA). At some predetermined times (2.5, 12, and 24 hours for MID-AC and 2.5, 6, 12 , and 24 hours for BPA), the animals were euthanized and each organ was removed. The concentration of boron in each organ was determined by ICP-AES. The mean concentration of boron values in each organ $(\mu \mathrm{g} \mathrm{B} / \mathrm{gram})$ and standard deviation are shown for each group of 3-5 rats. 


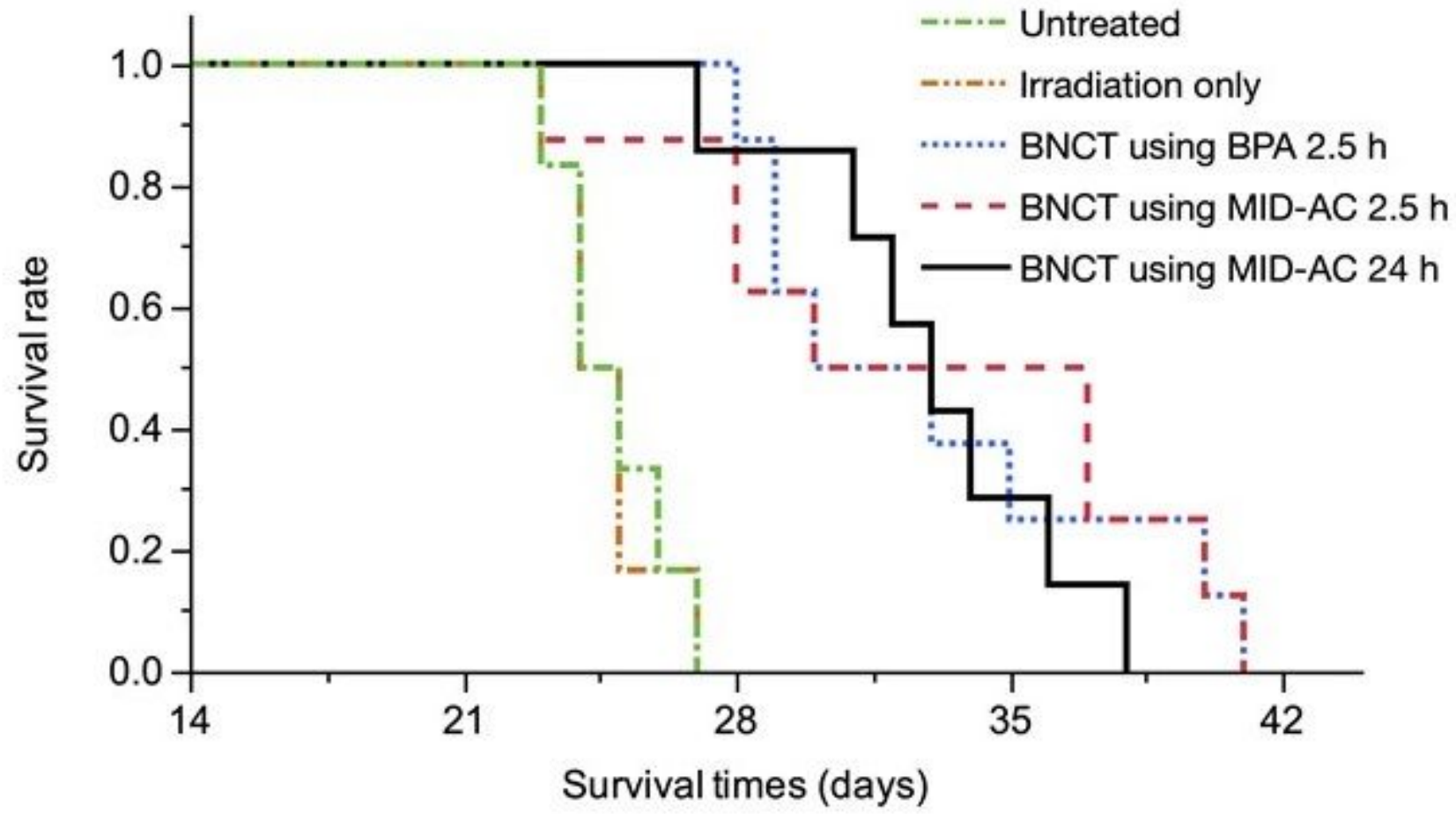

Figure 2

Kaplan-Meier survival curves for F98 rat glioma models after the neutron irradiation experiment. Survival times in days after implantation of F98 rat glioma cells have been plotted for following 5 groups; Untreated, Irradiation only, BNCT using boronophenylalanine (BPA) $2.5 \mathrm{~h}, \mathrm{BNCT}$ using maleimidefunctionalized closo-dodecaborate albumin conjugate (MID-AC) $2.5 \mathrm{~h}$, and BNCT using MID-AC $24 \mathrm{~h}$. The results showed that there were statistically significant differences between the 3 neutron irradiation groups following boron compounds administration and Untreated (vs. BNCT using BPA $2.5 \mathrm{~h}, \mathrm{p}<0.0001$; vs. BNCT using MID-AC 2.5h, $p=0.0019$; vs. BNCT using MID-AC $24 \mathrm{~h}, \mathrm{p}=0.0005$, respectively, log-rank test). There was no significant difference between BNCT using MID-AC $2.5 \mathrm{~h}$ or $24 \mathrm{~h}$ and BNCT using BPA (vs. BNCT using MID-AC 2.5h, $p=0.94$; vs. BNCT using MID-AC 24h, $p=0.67$, respectively, log-rank test). 